\title{
The role of joint line position and restoration of posterior condylar offset in revision total knee arthroplasty : a systematic review of $\mathbf{4 2 2}$ revision knees arthroplasty
}

\author{
Hany Elbardesy, André McLeod, Rehan Gul, James Harty
}

From the Department of trauma and orthopaedic, Cork University Hospital, Cork, Ireland

The aim of this systematic review was to evaluate the evidence on reservation of Posterior Femoral Condylar Offset (PFCO) and Joint Line (JL) after Revision Total Knee Arthroplasty (RTKA) for improved functional outcomes.

A comprehensive search of PubMed, Medline, Cochrane, CINAHL, and Embase databases was conducted, with papers published from the inception of the database to October 2020 included. All relevant articles were retrieved, and their bibliographies were hand searched for further references on Posterior condylar offset and revision total knee arthroplasty. The search strategy yielded 28 articles. After duplicate titles were excluded, abstracts and full text were reviewed. Nine studies were assessed for eligibility, four studies were excluded because they did not fully comply with the inclusion criteria. Six articles were finally included in this systematic review.

Based on this systematic review restoration of the $\mathrm{JL}$ and PFCO in RTKR is associated with a significant improvement in the post-operative range of motion, KSS, OKS, patellar function, and SF-36.

Reservation of $\mathrm{JL}$ should be a major consideration when undertaking RTKA. Of note, increasing PFCO to balance the flexion gap while maintaining joint line should be well assessed intra-operatively. The upper limit of the PFCO that widely accepted is up to $40 \%$ greater than that of the native knee. $4 \mathrm{~mm}$ is the upper limit for $\mathrm{JL}$ restoration.

Conflict of interest : The authors declare no conflicts of interest.

Ethical approval This article does not contain any studies with human or animal participants performed by any of the authors.
Level of evidence III.

Keywords : revision total knee arthroplasty ; total knee replacement; joint line; posterior femoral condylar offset.

\section{INTRODUCTION}

The number of Total Knee Arthroplasty (TKA) performed has dramatically increased in recent years with 108,506 TKAs performed in 2019 in the United Kingdom alone (1). Along with this increase in TKAs there has also been an increase in revision total knee arthroplasties (RTKAs). While there have been advances in revision arthroplasty, the outcomes of RTKAs are naturally inferior to primary TKA $(1,2)$. Restoration of the joint line (JL) after primary TKA is associated with better functional outcomes

Hany Elbardesy, MSc, MRCS, FRCS(Tr\&Orth) FEBOT,

André McLeod, MRCS

Rehan Gul, FRCS

- James Harty, FRCS

Department of trauma and orthopaedic, Cork University Hospital, Cork, Ireland.

Correspondence: Hany Elbardesy, Department of trauma and orthopaedic, Cork University Hospital, Cork, Ireland. Phone: +353214922000. ORCID ID : https://orcid.org/ 0000-0001-8600-6339.

Email : elbardecy@hotmail.com

• 2021, Acta Orthopædica Belgica.

Acta Orthopædica Belgica, Vol. 87 - 3 - 2021 
and inability to maintain the joint line in RTKA has been shown to result in reduced functional outcomes $(3,4,5)$. Joint line elevation is also related to an increase in patellofemoral joint contact forces (6). Elevation of the joint line in RTKA often occurs due to failure to address the distal femoral bone loss with appropriate femoral augments $(4,5,7)$. As well as joint line preservation, restoration of posterior Femoral Condylar Offset (PFCO) is also a vital aspect of RTKA, as it provides flexion stability and enhances the postoperative range of movement (ROM) (8-10). However, restoration of PFCO during RTKA is a challenge due to posterior femoral condylar bone loss, as it consequently leads to under sizing of the femoral component (11). A thicker polyethylene insert is then subsequently required in order to maintain stability in both flexion and extension, with the disadvantage of elevating the joint line (11). Inadequate PFCO also allows for posterior tibiofemoral impingement which can restrict knee flexion and predispose to flexion instability $(8,9)$. A combination of these factors subsequently leads to poorer clinical and functional outcomes $(5,12,13)$. Another important consideration in RTKA is the use intramedullary stems. Due to the bone loss associated with RTKA, intramedullary femoral stems are often used to provide implant stability, and the position of these stems dictates both the medio-lateral and antero-posterior positioning of the condylar part of the femoral component (14). Most stems are attached to the femoral component at a fixed valgus angle of $5-7^{\circ}$ in the frontal plane and perpendicular in the lateral plane. While the distal femur is bowed anteriorly, a straight diaphyseal engaging stem would be anticipated to displace the femoral component anteriorly. This could cause inadequate PFCO, which dictates either the use of an oversized femoral component or the use of a smaller diameter cemented stem to fill the flexion space $(15,16)$. The aim of this systematic review is to analyze the current literature to identify the best available evidence on the effect of PFCO and restoration of anatomical joint line on early joint specific functional outcomes after RTKA.

\section{METHODS}

A systematic review of the literature was performed according to the Preferred Reporting Items for Systematic Reviews and Meta-analyses guidelines (PRISMA) (17). A comprehensive search of the PubMed, CINAHL, Medline, Cochrane, Ovid, Embase, and Google Scholar databases was performed using the following combinations of the keywords : Joint line position, revision total knee arthroplasty, offset stem and, posterior condylar offset. Articles published up to October 2020 were included in our literature search and we limited papers to studies in human subjects published in any language. Additionally, we cross-referenced the bibliographies of retrieved articles and review papers to ensure that we captured all relevant studies. The quality of the evidence was classified using the US Preventive Services Task Force system for ranking the level of evidence (18).

Three authors (HE, AM and RG) independently screened all titles and abstracts identified by the initial search to assess their eligibility for inclusion. Then we did a full screening of the manuscript and conducted a final evaluation of a study's eligibility. After all eligible manuscripts had been evaluated for inclusion, data extraction was conducted by the same two reviewers. Any discrepancies with collected data were resolved by consensus between the three reviewers.

Categorical variable data were reported as the frequency with percentage. Continuous variable data were reported as mean value, with the range between minimum and maximum values.

We used the modified Coleman Methodology Score (mCMS) to assess the quality of each study, it assesses methodology using 10 different criteria, giving a total score ranging between 0 and 100 points. A score of 100indicates that the study largely avoids various biases, chance ,and confounding factors. The final score can be defined as excellent (85 to 100 points), good (70 to 84 points), fair (50 to 69 points), and poor ( $<50$ points). The subcategories that make up the mCMS are based on the subcategories of the CONSORT statement and were modified to accept for other trial designs. Each study was independently scored by two reviewers 
and in triplicate for each of the criteria adopted to give a total mCMS between 0 and 100 .

\section{RESULTS}

The selection process is illustrated in Fig. 1. The literature search and cross-referencing resulted in a total of 28 references, of which 13 were rejected because they did not fully comply with the inclusion criteria. After reading the remaining full-text articles, the other 8 articles were excluded because of insufficient details and uncertain diagnosis and outcome measures.

There were five studies $(12,14,19-21)$ of Level of Evidence (LoE) III and one study (22) of LoE IV. The mean value of the CMS score was 52.5 points, showing that the mean quality of the included study was fair. Detailed values of the Coleman score are reported in Table 1. No statistically significant difference was found between mean values of CMS calculated by the two examiners.

The 6 studies selected were published from 2006 to 2019. Articles included a total of 422 knees, with a median age of 65.87 years (range 56.7-92 years). Patient demographics and study characteristics are illustrated in Tables 2 and 3.

The PFCO is defined as the distance between the maximal thickness of the posterior condyle projected

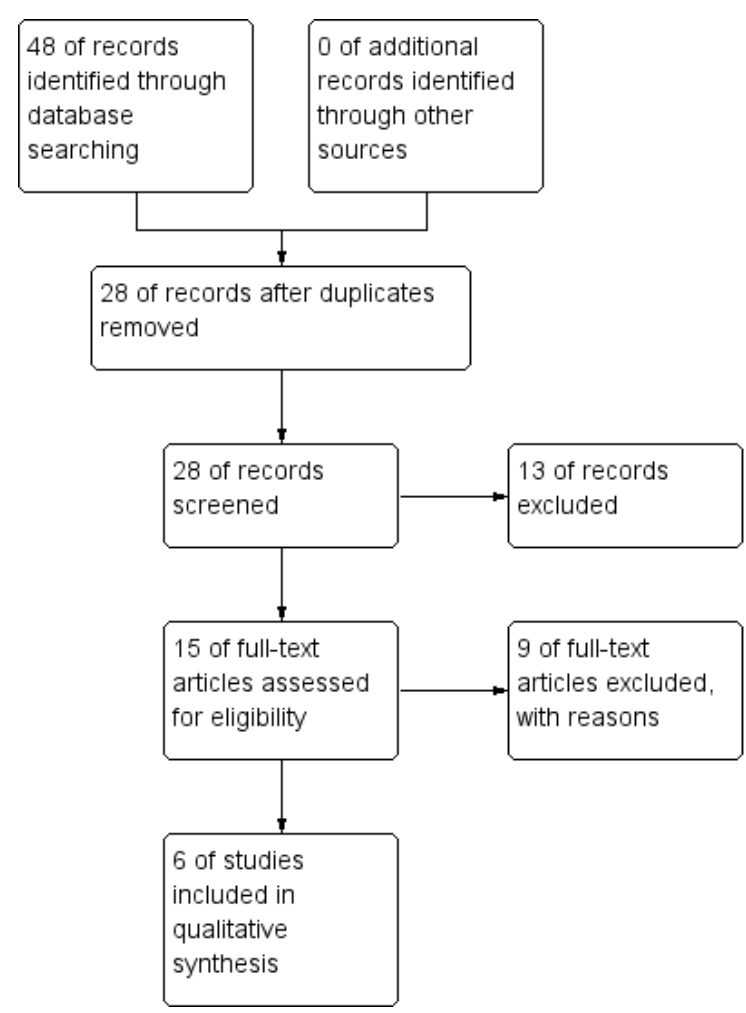

Figure 1. - Preferred reporting items for systematic reviews and meta-analyses (PRISMA) flow chart.

posteriorly and the tangent of the posterior cortex of the femoral shaft on the true lateral radiographs (8).

Table 1. - Coleman score calculated on the 6 articles included

\begin{tabular}{|c|c|c|c|c|c|c|}
\hline Section score & $\begin{array}{l}\text { Clement } \\
\text { et al } 2017\end{array}$ & $\begin{array}{l}\text { Hofmann } \\
\text { et al } 2006\end{array}$ & $\begin{array}{l}\text { Innocenti } \\
\text { et al } 2013\end{array}$ & $\begin{array}{l}\text { Mahoney } \\
\text { et al } 2006\end{array}$ & $\begin{array}{c}\text { Ng et al } \\
2019\end{array}$ & $\begin{array}{c}\text { Hitt et al } \\
2015\end{array}$ \\
\hline \multicolumn{7}{|l|}{ Part A } \\
\hline Study size & 10 & 7 & 4 & 0 & 10 & 7 \\
\hline Mean follow up & 4 & 10 & 7 & 7 & 0 & 0 \\
\hline Number of different versions of the implant used & 7 & 7 & 0 & 7 & 0 & 10 \\
\hline Type of study & 0 & 0 & 0 & 0 & 0 & 0 \\
\hline Description of indications (diagnostic certainty) & 5 & 5 & 5 & 5 & 5 & 5 \\
\hline Description of surgical procedure & 10 & 5 & 10 & 5 & 10 & 10 \\
\hline Description of postoperative rehabilitation & 0 & 0 & 0 & 0 & 0 & 0 \\
\hline \multicolumn{7}{|l|}{ Part B } \\
\hline Outcome criteria & 10 & 10 & 10 & 10 & 0 & 10 \\
\hline Procedure of assessing outcomes & 12 & 12 & 12 & 12 & 0 & 15 \\
\hline Description of subject selection process & 5 & 5 & 5 & 5 & 0 & 5 \\
\hline Total score & 63 & 61 & 53 & 51 & 25 & 62 \\
\hline
\end{tabular}


Table 2. - Study characteristics, TS : Total Stabiliser

\begin{tabular}{|l|l|c|c|l|}
\hline Study & Journal & Type of study & Numbers & Prosthesis type \\
\hline Clement et al 2017 & Bone Joint Res & RCS & 107 & Kinemax Plus Total Stabiliser (TS), Triathlon TS \\
\hline Hofmann et al 2006 & The Journal of Arthroplasty & RCS & 89 & Natural Knee; Zimmer, Warsaw, Ind \\
\hline Innocenti et al 2013 & The Knee & RCS & 43 & $\begin{array}{l}\text { Legion; Smith \& Nephew, Memphis, TN(25 (62.5\%) } \\
\text { POS and 15 (37.5\%) with a straight stem) }\end{array}$ \\
\hline Mahoney et al 2006 & Clin Orthop Relat Res & RCS & $29-22$ & Scorpio, Stryker \\
\hline Ng et al 2019 & The Knee & RCS & 172 & Triathlon TS system \\
\hline Hitt et al 2015 & The Journal of Knee Surgery & RCS & 96 & Triathlon TS system \\
\hline
\end{tabular}

Table 3. - Patients demographics

\begin{tabular}{|c|c|c|c|c|c|}
\hline Study2 & $\begin{array}{c}\text { Gender } \\
\text { F/MI }\end{array}$ & Age & PROM & Reasons for revision & Follow Up \\
\hline $\begin{array}{l}\text { Clement et al } \\
2017\end{array}$ & $59 / 48$ & $69.4(39-85)$ & $\begin{array}{l}\text { OKS, (SF)- } \\
12, \text { PCO }\end{array}$ & $\begin{array}{l}\text { instability, polyethylene wear, and/or lysis/ } \\
\text { subsidence of the primary implant. }\end{array}$ & one year \\
\hline $\begin{array}{l}\text { Hofmann et al } \\
2006\end{array}$ & $42 / 41$ & $67(32-86)$ & $\begin{array}{c}\text { ROM, } \\
\text { KSS,PCO }\end{array}$ & $\begin{array}{l}35 \text { aseptic loosening, } 25 \text { infection, } 31 \text { for } \\
\text { instability. } 10 \text { impingements, PF problems, } \\
\text { polyethylene wear, malalignment, or poor } \\
\text { motion. }\end{array}$ & 8.2 years $(24-197 \mathrm{~m})$ \\
\hline $\begin{array}{l}\text { Innocenti et al } \\
2013\end{array}$ & $29 / 11$ & $68.8(43-87)$ & $\begin{array}{c}\text { KSS, } \\
\text { PCO,ROM }\end{array}$ & $\begin{array}{l}\text { aseptic loosening (29), infection (10), femoral } \\
\text { com-ponent malposition (2), and stiffness } \\
\text { with pain (2). }\end{array}$ & $3.5(0.7-5.5)$ years. \\
\hline $\begin{array}{l}\text { Mahoney et al } \\
2006\end{array}$ & $16 / 6$ & $\begin{array}{l}70.5 \pm 10.6 \\
(38.2-85.4)\end{array}$ & $\begin{array}{c}\text { KSS, } \\
\text { PCO,ROM }\end{array}$ & $\begin{array}{l}\text { aseptic loosening (9), loosening of revised } \\
\text { components from a previously infected knee } \\
\text { (2), instability (4), infection (4), stiffness with } \\
\text { pain (1), and periprosthetic fracture (2). }\end{array}$ & $4.8(4.8-5.5)$ years \\
\hline $\mathrm{Ng}$ et al 2019 & NA & NA & ROM,PCO & NA & NA \\
\hline Hitt et al 2015 & $44 / 51$ & $67.5(49-92)$ & $\begin{array}{l}\text { ROM, LEAS, } \\
\text { SF-36, HSS } \\
\text { Patella Pain, } \\
\text { and KOOS }\end{array}$ & $\begin{array}{l}\text { septic }(8,8.5 \%) \text { or aseptic }(86,91.5 \%) \\
\text { failure, } \\
\text { with } 2 \text { cases not categorized. }\end{array}$ & 6 months \\
\hline
\end{tabular}

The offset stem can be positioned at the link between the body of the stem and its point of attachment to the prosthesis base. Femoral offset options are $2 \mathrm{~mm}$ and $4 \mathrm{~mm}$ for Triathlon TS (Stryker, Mahwah, NJ) ; $2 \mathrm{~mm}$ and $4 \mathrm{~mm}$ for TC3 Sigma (DePuy, Warsaw, IN) ; $2 \mathrm{~mm}, 4 \mathrm{~mm}$, and $6 \mathrm{~mm}$ for Legion (Smith \& Nephew, Memphis, TN) ; and $4.5 \mathrm{~mm}$ for LCCK (Zimmer, Warsaw, IN) (23).

There is no standard anatomical measuring system to correctly identify the joint line. Some authors described it as the distance from the adductor tubercle to the joint line of the distal femur, while others measure it from the lateral flare instead. Some surgeons calculate it on AP view, though others measure it on the lateral view from the posterior flare of the femoral condyle distal to the joint line. As well others measure it from the tip of the fibular head proximal to the proximal tibial surface, or from the tibial tubercle proximal to the joint surface $(7,12)$.

Of the included studies, reported outcomes included post-operative ROM, functional assessments including Knee Society Score (KSS), Oxford Knee Score (OKS) and other PROMs.

Overall, four studies $(12,14,19,21)$ including 250 RTKAs reported on postoperative ROM. The mean total flexion arc significantly improved in all three studies at the time of the latest follow-up (Table 3). Another study (22), comprising of 172 RTKAs, reported a significant correlation between sagittal alignment of the femoral component and PFCO $(\mathrm{r}=0.39, \mathrm{P}<0.0001)$, within creasing flexion 
Table 4. - Range Of Movement (ROM) comparison

\begin{tabular}{|c|c|c|c|c|c|c|}
\hline Column1 & $\begin{array}{c}\text { Preoperative } \\
\text { Flexion }\end{array}$ & $\begin{array}{c}\text { Postoperative } \\
\text { flexion }\end{array}$ & $\begin{array}{c}\text { Preoperative } \\
\text { extension }\end{array}$ & $\begin{array}{c}\text { postoperative } \\
\text { extension }\end{array}$ & $\begin{array}{c}\text { Preoperative Arc of } \\
\text { Motions }\end{array}$ & $\begin{array}{l}\text { postoperative } \\
\text { Arc of Motions }\end{array}$ \\
\hline Hofmann 2006 & $96(40-135)$ & $106(45-135)$ & $6(08-35)$ & $2(0-20)$ & NA & NA \\
\hline Innocenti 2013 & $78.2 \pm 23.6$ & $108^{\circ}\left(55-140^{\circ}\right)$ & NA & NA & NA & NA \\
\hline Mahoney 2006 & $\begin{array}{c}78.2 \pm 23.6 \\
(15-105)\end{array}$ & $\begin{array}{c}106.3 \pm 15.9 \\
(65-135)\end{array}$ & $\begin{array}{l}8.5 \pm 8 \\
(0-25)\end{array}$ & $\begin{array}{l}1.2 \pm 2.5 \\
(0-10)\end{array}$ & $\begin{array}{c}69.7 \pm 28.7 \\
(10-100)\end{array}$ & $\begin{array}{c}105.1 \pm 16.9 \\
(62-135)\end{array}$ \\
\hline Hitt et al 2015 & NA & NA & NA & NA & 94.6 & 106.3 \\
\hline
\end{tabular}

Table 5. - Comparison between preoperative and postoperative KSS score

\begin{tabular}{|l|c|c|}
\hline Study & Preoperative KSS & Postoperative KSS \\
\hline Hofmann 2006 & $120(60-176)$ & $188(140-200)$ \\
\hline Innocenti 2013 & $33(21-45)$ & $83(62-95)$ \\
\hline Mahoney 2006 & $32.9 \pm 18.9(1-68)$ & $90.7 \pm 9.5(70-100)$ \\
\hline
\end{tabular}

being associated with increased PFCO. This study highlights the fact that intentionally flexing the revision component can increase the $\mathrm{PFCO}$ ratio leading to more ROM by providing more flexion stability.

Three studies $(12,14,19)$, reported on KSS with a total of 154 RTKAs. They reported significant improvement after restoration of the JL and PFCO (Table 4).

One study (24), reported OKS including a total of 43RTKAs. The OKS (mean, SD) improved from 40.6 (7.7) to 30.0 (11.1) with mean difference 10.6 (range 8.8 to 12.4$)(\mathrm{P}<0.0001)$. Linear regression analysis confirmed the independent effect of PFCO on the OKS $(\mathrm{p}<0.001)$.An increase in PFCO ratio was associated with a greater improvement in the OKS for both the Kinemax $(r=0.43, p<0.001$ Pearson) and Triathlon $(\mathrm{r}=0.45, \mathrm{p}<0.001$, Pearson $)$ groups.

One study (21), highlighted the improvements in Short Form-36 (SF-36), Knee Injury and Osteoarthritis Outcomes Score (KOOS), Hospital for Special Surgery (HSS) Patella Score and Lower Extremity Activity Scale (LEAS)scores at 6 months and Knee Society Score (KSS) at 6 weeks follow up. These were compared with corresponding preoperative values. SF-36 physical component score showed a significant improvement in function, though SF-36 mental component score (MCS) indicated similar mental health status before and after revision. All patients reported a reduction in knee pain, less noise in the patellar femoral joint, and improvement in patellar function (Table 5).

Table 6. - Improvement in clinical outcomes scores, ADL (Activities of Daily Living), SYMPT (Symptoms), REC (Recreations), QOL (Quality of Life)

\begin{tabular}{|l|c|c|c|}
\hline Outcome score & Preoperative & 6-months Post-operative & p-value \\
\hline LEAS: scale (0-18) & $7.7(2.64)$ & $8.81(2.36)$ & 0.0027 \\
\hline SF-36: mental component score (50 normal mean) & $48.09(14.37)$ & $51.28(13.42)$ & 0.1137 \\
\hline SF-36: physical component score (50 normal mean) & $31.42(7.79)$ & $40.11(11.22)$ & $<0.0001$ \\
\hline HSS patella: scale (0-100) & $47.14(15.19)$ & $73.92(21.8)$ & $<0.0001$ \\
\hline KOOS_PAIN & $42.55(20.20)$ & $72.26(24.22)$ & $<0.0001$ \\
\hline KOOS_SYMPT & $48.88(20.11)$ & $73.67(18.43)$ & $<0.0001$ \\
\hline KOOS_ADL & $45.59(21.32)$ & $73.10(24.41)$ & $<0.0001$ \\
\hline KOOS_SPORT,REC & $10.36(18.36)$ & $36.79(28.79)$ & $<0.0001$ \\
\hline KOOS_QOL & $20.34(20.42)$ & $52.79(27.11)$ & $<0.0001$ \\
\hline
\end{tabular}




\section{DISCUSSION}

The results of this meta-analyses support the view that accurate restoration of $\mathrm{JL}$ and PFCO result in significantly improved clinical outcomes. Some authors claimed that restoration of the JL within $5 \mathrm{~mm}$ of the original position is acceptable $(4,5)$. However, none of these authors analysed the effect of PFCO on the postoperative outcome of RTKA. It may be that patients who had their joint line restored also had enough PFCO to balance the knee in flexion. PFCO can be restored with either the use of an oversized femoral component, a flexed stemmed implant that posteriorly displaces the condylar component or a posterior offset stem coupler. However, the use of an oversized component may cause soft-tissue impingement resulting in postoperative pain (25). The use of intramedullary stems for implant stability may change the anteroposterior position of the femoral condylar component (14). Stem flexion may result in anterior bony impingement between the proximal uncemented stem tip and anterior femoral cortex, which may cause to stem tip pain (26). This can be avoided with the use of modified hybrid cementing techniques (27). The restoration of the PFCO has proved to be associated with preferable outcomes after primary TKA $(8,9)$. Johal et al. (28) state that the normal PFCO ratio is 0.80 , while Clement et al. (24) stated that the mean PFCO ratio for the Kinemax TS and Triathlon knees were 0.86 and 1.04 respectively, which is greater than that predicted for the patients' native knee. In RTKA, the posterior cruciate ligament (PCL) is usually excised and the popliteus tendon often loses its insertion due to condylar bone loss. Additionally, the posterior capsule is also often disrupted. Expanding the PFCO beyond that of the native knee probably compensates for this softtissue disruption and permits for a non-linked semi constrained RTKA to be used (29). The acceptable upper limit of PFCO is up to $40 \%$ greater than that of the native knee, without much improvement in OKS beyond that limit (24). Moreover, $4 \mathrm{~mm}$ is the upper limit for JL restoration (12). Patients with their JL moved proximally or distally more than $4 \mathrm{~mm}$ from the measured preoperative value post RTKA had dependent variables of outcomes that were statistically compromised. Accurate restoration of the JL produced excellent clinical results at an average follow-up of 8.2 years (12). Moreover, Mahoney et al. mentioned that JL restoration within $5 \mathrm{~mm}$ of the desired anatomic joint position in a consecutive series of 22 RTKAs using modular femoral offset stems was also acceptable (14). JL elevation was also shown to be associated with decreased ROM, poor extensor power, anterior knee pain, patellar instability and mid-flexion instability (5,6,12,30-33). In RTKA, surgeons are commonly left with a larger flexion space than extension space after component removal. The capsuloligamentous structures that are effective in extension are usually much better preserved than those that control the knee in flexion. To achieve a balanced flexion and extension gap, the surgeon might decide to fill the excess flexion space by applying a thicker insert, and may make a compensatory increase in the extension space by proximizing the femoral component, resulting in JL elevation (11). Some authors quantified that 50-80\% of RTKA patients have JL elevation $(5,12,30-32)$. The revision burden of TKA will likely continue to rise in the future, and the optimal outcome is to limit patient disability. Preservation of JL and optimal increasing of PFCO to balance the flexion gap should be major considerations when undertaking RTKA.

\section{STUDY LIMITATIONS}

The volume of data used in this study was relatively low. Another source of limitation included the inclusion of retrospective studies without any randomised control studies. As with this retrospective study, these types of observational patterns are more susceptible to bias in data collection and are confronted by the incompetence to control for all the variables measured between the different cohorts included in each study.

\section{CONTRIBUTORS}

All authors had made impactful contributions to the manuscript submitted. HE is the primary author of said manuscript. He made substantial contributions to the design of the work, acquisition 
of data, analysis/interpretation, and writing the manuscript. RG and AM they played an integral role in selecting included studies during the screening process. They provided necessary guidance, support and mentorship throughout the whole process.AM was involved in study design, statistical analysis and revising intellectual property. $\mathrm{JH}$ played an integral role for this study. They provided necessary guidance, support and mentorship throughout the whole process. He was involved in study design, statistical analysis and revising the intellectual property.

\section{REFERENCES}

1. Brittain R. et al. 17th Annual Report. Natl. Jt. Regist. England, Wales, North. Irel. Isle Man, 2019 Dec ; 120-193.

2. Australian Orthopaedic Association National Joint Replacement Registry. Australian Orthopaedic Association National Joint Replacement Registry (AOANJRR). Hip, knee \& shoulder arthroplasty - Annual Report 2018 ; 1-444.

3. Babazadeh S,. Dowsey MM, Swan JD, Stoney JD, Choong PFM. Joint line position correlates with function after primary total knee replacement. J. Bone Joint Surg. Br., 2011 Sep ; 93-B (9) : 1223-1231.

4. Seon JK and Song EK. Joint line and patellar height restoration after revision total knee arthroplasty. Indian $J$. Orthop. 2016 ; 50 (2) : 159 ..

5. Porteous AJ, Hassaballa MA, and Newman JH. Does the joint line matter in revision total knee replacement? J. Bone Joint Surg. Br. 2008 Jul ; 90-B (7) : p. 879-884.

6. König C. et al. Joint line elevation in revision TKA leads to increased patellofemoral contact forces. J. Orthop. Res. p. n/a-n/a, 2009.

7. Hoeffel DP, Rubash HE. Revision total knee arthroplasty : current rationale and techniques for femoral component revision. Clin. Orthop. Relat. Res. 2000 Nov ; 380 : 116-32.

8. Bellemans J, Banks S, Victor J, Vandenneucker H, Moemans A. Fluoroscopic analysis of the kinematics of deep flexion in total knee arthroplasty. J. Bone Jt. Surg. 2002 Jan ; 84 (1) : 50-53.

9. Malviya A, Lingard AE, Weir DJ, Deehan DJ. Predicting range of movement after knee replacement : the importance of posterior condylar offset and tibial slope. Knee Surgery, Sport. Traumatol. Arthrosc.2009 May ; 17 (5) : 491-498.

10. Massin P, Gournay A. Optimization of the Posterior Condylar Offset, Tibial Slope, and Condylar Roll-back in Total Knee Arthroplasty. J. Arthroplasty. 2006 Sep ; 21 (6) : 889-896.

11. Bellemans J. Restoring the joint line in revision TKA : does it matter? Knee. 2004 Feb ; 11 (1) : 3-5.
12. Hofmann AA, Kurtin SM, Lyons S, Tanner AM, Bolognesi MP. Clinical and Radiographic Analysis of Accurate Restoration of the Joint Line in Revision Total Knee Arthroplasty. J. Arthroplasty. 2006 ; 21 (8) : 11541162.

13. Han HS, Yu CH, Shin N, Won S, Lee MC. Femoral joint line restoration is a major determinant of postoperative range of motion in revision total knee arthroplasty. Knee Surgery, Sport. Traumatol. Arthrosc. 2019 ;27(7) : 20902095.

14. Mahoney OM, Kinsey TL. Modular femoral offset stems facilitate joint line restoration in revision knee arthroplasty. Clin. Orthop. Relat. Res. 2006 ; 446 :93-98.

15. Ries MD, Haas SB and Windsor. Soft-Tissue Balance in Revision Total Knee Arthroplasty. J. Bone Jt. Surgery-Am $2004 ; 86: 81-86$.

16. Niki Y, Sassa T, Nagai K, Harato K, Kobayashi S, Yamashita T. Mechanically aligned total knee arthroplasty carries a risk of bony gap changes and flexion-extension axis displacement. Knee Surgery, Sport. Traumatol. Arthrosc. 2017 Nov ; 25 (11) : 3452-3458.

17. Julian JT, Higgins PT, Jacqueline Chandler TL, Cumpston M. et al. Cochrane Handbook for Systematic Reviews of Interventions. 2019.

18. A. J. P. Med. "Level of evidence provided by us preventive services task force," 2001.

19. Innocenti M, Matassi F, Carulli C. et al. Joint line position in revision total knee arthroplasty: The role of posterior femoral offset stems. Knee $2013 ; 20(6)$ : 447-450.

20. Clement ND, MacDonald DJ, Hamilton DF, Burnett R. Posterior condylar offset is an independent predictor of functional outcome after revision total knee arthroplasty. Bone Jt. Res. 2017 ; 6(3) :172-178.

21. Hitt K, Bhowmik-Stoker M, Howard M, Mittal Y, Heekin RD, Jacofsky D. Joint line restoration in a contemporary revision knee system. J. Knee Surg. 2015 ; 28 (1) : 75-82.

22. Ng N, Patton JT, Burnett R, Clement ND. Sagittal alignment of the cemented femoral component in revision total knee arthroplasty influences the anterior and posterior condylar offset : Stem length does not affect these variables. Knee. 2020 ; 27(2) : 477-484.

23. Baldini A, Balato G, Franceschini V. The role of offset stems in revision knee arthroplasty. Curr. Rev. Musculoskelet. Med. $2015 ; 8$ (4) : 383-389.

24. MacDonald SJ, Charron KD, Bourne RB, Naudie DD, McCalden RW, Rorabeck CH. The John Insall Award : Gender-specific Total Knee Replacement: Prospectively Collected Clinical Outcomes. Clin. Orthop. Relat. Res. 2008 Nov ; 466 (11) : 2612-2616.

25. Barrack RL, Rorabeck C, Burt M, Sawhney J. Pain at the end of the stem after revision total knee arthroplasty. Clin. Orthop. Relat. Res. 1999 Oct ; 367 : 216-25.

26. Kim MS, Koh IJ, Sohn S, Park HC, In Y. Modified hybrid cementing technique reduces stem tip pain and improves 
patient's satisfaction after revision total knee arthroplasty. J. Orthop. Surg. Res. 2020 Dec ; 15 (1) : 393.

27. Johal P, Hassaballa MA, Eldridge JD, Porteous AJ. The Posterior Condylar Offset Ratio. Knee. 2012 Dec ; 19 (6) : 843-5.

28. Mitsuyasu H. et al. Enlarged postoperative posterior condyle tightens extension gap in total knee arthroplasty. $J$. Bone Joint Surg. Br. 2011 Sep ; 93-B (9) : 1210-1216.

29. Partington PF, Sawhney J, Rorabeck CH, Barrack RL, Moore J. Joint line restoration after revision total knee arthroplasty. Clin. Orthop. Relat. Res., 1999 Oct; 367 ; 165-71.
30. Figgie HE, Goldberg VM, Heiple KG, Moller HS, Gordon NH. The influence of tibial-patellofemoral location on function of the knee in patients with the posterior stabilized condylar knee prosthesis. J. Bone Joint Surg. Am. 1986 Sep ; 68 (7) : 1035-40.

31. Laskin RS. Joint Line Position Restoration During Revision Total Knee Replacement. Clin. Orthop. Relat. Res. 2002 Nov ; 404 :169-171.

32. Khakharia S, Scuderi GR. Restoration of the Distal Femur Impacts Patellar Height in Revision TKA. Clin. Orthop. Relat. Res. 2012 Jan ; 470(1) : 205-210 